\title{
ON THE EXISTENCE AND UNIQUENESS OF SOLUTIONS OF STOCHASTIC INTEGRAL EQUATIONS OF THE VOLTERRA TYPE
}

\author{
By ICHIRO ITO
}

\section{Introduction}

The theory of stochastic integral equations has been studied from two principal points of view. One is the theory of Itô stochastic differential equations which is an important problem in stochastic processes and has been investigated in detail as presented in the books of Friedman [2] and Gihman and Skorohod [3], among others. The other approach to stochastic integral equations is to consider them as probabilistic versions of classical deterministic integral equations and investigate them using functional analytic concepts and methods (see [1], [6], [7]). As shown in the book of Tsokos and Padgett, the equations which have been discussed in the latter manner are also important in stochastic characterization of physical situations, and have been studied by many authors.

In the previous research [4], the present author studied linear stochastic integral equations belonging to the latter class of equations by the method analogous to those used in the theory of Itô stochastic differential equations. Although, the argument applied there is available in nonlinear cases as well as in the linear case. And in this paper we shall discuss general stochastic integral equations of the Volterra type. The class of equations at issue is a vast one which includes both Itô stochastic differential equations and nonlinear Volterra integral equations (see [5]). We shall establish the existence and uniqueness of stochastic processes with continuous sample paths with probability one as solutions of equations, which is a generalization of the corresponding theorems in the theory of stochastic differential equations.

Let $B(t)(t \geqq 0)$ be a one-dimensional Brownian motion on a probability space $(\Omega, F, P)$. Let $F_{t}(t \geqq 0)$ be an increasing family of $\sigma$-fields such that $F_{t_{1}} \subset F_{t_{2}}$ if $t_{1} \leqq t_{2}, \sigma(B(s), 0 \leqq s \leqq t)$ be in $F_{t}$, and $\sigma(B(t+s)-B(t), s \geqq 0)$ be independent of $F_{t}$ for all $t \geqq 0$. We shall be concerned with a stochastic integral equation of the Volterra type given by

$$
x(t)=\phi(t)+\int_{0}^{t} f(t, s, x(s)) d B(s)+\int_{0}^{t} g(t, s, x(s)) d s, \quad 0 \leqq t \leqq T,
$$

Received December 17, 1977 
where $\phi(t)$ is a given $F_{t}$-adapted continuous process, and $f(t, s, x)$ and $g(t, s, x)$ are random functions defined for $0 \leqq s \leqq t \leqq T$ and $-\infty<x<\infty$. The first integral on the right-hand side of (I) should be understood as the Itô integral.

The stochastic process $x(t)$ will be said to be a solution of (I) on $[0, T]$ if it is a $F_{t}$-adapted continuous process for which the integrals on the right-hand side of (I) are well defined, and (I) is satisfied for all $t \in[0, T]$ with probability one. Here the continuous process means that the sample paths are continuous functions with probability one.

In section 2 we shall investigate integral transformations by the stochastic, integral and obtain maximal inequalities which are necessary in the later sections. In section 3 we shall establish the existence and uniqueness of the solutions. And in section 4, we shall obtain stronger results by weakening the assumptions of the theorem in section 3 .

The author wishes to express his sincere thanks to Prof. K. Kawamura for kind encouragement and to Dr. S. Mase for helpful advices.

\section{Maximal Inequality}

In this section we shall investigate the integral transformation

$$
I(t)=\int_{0}^{t} f(t, s, x(s)) d B(s), \quad 0 \leqq t \leqq T,
$$

under the following assumptions with respect to the random functions $f(t, s, x)$ defined for $0 \leqq s \leqq t \leqq T$ and $-\infty<x<\infty$ :

(A1) $f(t, s, x)$ is continuous in $(t, s, x)$ for each $\omega$,

(A2) $f(t, s, x)$ is $F_{s}$-measurable for each $(t, s, x)$.

There is a constant $K$ such that

(A3) $|f(t, s, x)| \leqq K(1+|x|)$ a.s.,

(A4) $\left|f\left(t, s, x_{1}\right)-f\left(t, s, x_{2}\right)\right| \leqq K\left|x_{1}-x_{2}\right|$ a.s.,

(A5) $\left|f\left(t_{1}, s, x\right)-f\left(t_{2}, s, x\right)\right| \leqq K\left|t_{1}-t_{2}\right|$ a.s. .

Let $x(t)$ be a $F_{t}$-adapted process with $\sup _{0 \leq t \leq T} E\left[x^{2}(t)\right]<\infty$, then from the assumptions it follows that $E\left[\int_{0}^{t}|f(t, s, x(s))|^{2} d s\right]<\infty$. Thus the integral transformation $I(t)$ is well defined and, from the definition (2.1), it is $F_{t}$-measurable. First we notice the following lemma.

LEMMA 2.1. If $\sup _{0 \leqq t \leqq T} E\left[x^{4}(t)\right]<\infty$, then the integral transformation $I(t), 0 \leqq$ $t \leqq T$, has a continuous version.

Proof. Let $0 \leqq u \leqq t \leqq T$, then using an estimate for stochastic integrals and the assumptions (A3) and (A5), we have

$$
\begin{aligned}
& E\left[|I(t)-I(u)|^{4}\right] \\
= & E\left[\mid \int_{0}^{u}\left(f(t, s, x(s))-f(u, s, x(s)) d B(s)+\left.\int_{u}^{t} f(t, s, x(s)) d B(s)\right|^{4}\right]\right.
\end{aligned}
$$




$$
\begin{aligned}
& \leqq 8 E\left[\left|\int_{0}^{u}(f(t, s, x(s))-f(u, s, x(s))) d B(s)\right|^{4}+\left|\int_{u}^{t} f(t, s, x(s)) d B(s)\right|^{4}\right] \\
& \leqq 8 \cdot 36 E\left[\left|\int_{0}^{u}\right| f(t, s, x(s))-\left.\left.f(u, s, x(s))\right|^{2} d s\right|^{2}+\left.\left.\left|\int_{u}^{t}\right| f(t, s, x(s))\right|^{2} d s\right|^{2}\right] \\
& \leqq 8 \cdot 36 E\left[u \int_{0}^{u}|f(t, s, x(s))-f(u, s, x(s))|^{4} d s+(t-u) \int_{u}^{t}|f(t, s, x(s))|^{4} d s\right] \\
& \leqq 8 \cdot 36 E\left[u \int_{0}^{u} K^{4}|t-u|^{4} d s+(t-u) \int_{u}^{t} K^{4}(1+|x(s)|)^{4} d s\right] \\
& \leqq 8 \cdot 36 K^{4}\left(T^{4}+8\left(1+\sup _{0 \leqq s \leqq T} E\left[x^{4}(s)\right]\right)\right)(t-u)^{2} .
\end{aligned}
$$

Consequently, Kolmogorov's lemma implies that $I(t)$ has a continuous version. This completes the proof.

From now on, the integral transformation $I(t)$ is always considered to be a continuous version of it.

Now let $x_{\imath}(t)(\imath=1,2)$ satisfy $\sup _{0 \leq t \leq T} E\left[x_{\imath}{ }^{4}(t)\right]<\infty$ and let $J(t)=\int_{0}^{t}\left\{f\left(t, s, x_{1}(s)\right)\right.$ $\left.-f\left(t, s, x_{2}(s)\right)\right\} d B(s), 0 \leqq t \leqq T$. The rest of this section is devoted to the derivation of maximal inequalities with respect to $J(t)$ and $I(t)$, which will be used in the proof of main theorems.

LEMMA 2.2. If $x_{i}(t)(\imath=1,2)$ satisfies $\sup _{0 \leqq t \leqq T} E\left[x_{\imath}{ }^{4}(t)\right]<\infty$, then

$$
P\left(\sup _{0 \leqq t \leqq T}\left|\int_{0}^{t}\left\{f\left(t, s, x_{1}(s)\right)-f\left(t, s, x_{2}(s)\right)\right\} d B(s)\right| \geqq \lambda\right) \leqq \lambda^{-4} K_{0} T^{2} C_{1},
$$

where $K_{0}$ is an absolute constant and

$$
C_{1}=288 K^{4}\left(16 T^{2} \sup _{0 \leqq t \leqq T} E\left[\left|x_{1}(t)-x_{2}(t)\right|^{2}\right]+\sup _{0 \leqq t \leqq T} E\left[\left|x_{1}(t)-x_{2}(t)\right|^{4}\right]\right) .
$$

Proof. This lemma can be derived by a similar argument to Lemma 1 in the author's previous paper [4]. We must remark the following estimate. If $0 \leqq u \leqq t \leqq T$, then

$$
\begin{aligned}
& E\left[|J(t)-J(u)|^{4}\right] \\
= & E\left[\mid \int_{0}^{u}\left\{\left(f\left(t, s, x_{1}(s)\right)-f\left(t, s, x_{2}(s)\right)\right)-\left(f\left(u, s, x_{1}(s)\right)-f\left(u, s, x_{2}(s)\right)\right)\right\} d B(s)\right. \\
& \left.+\left.\int_{u}^{t}\left\{f\left(t, s, x_{1}(s)\right)-f\left(t, s, x_{2}(s)\right)\right\} d B(s)\right|^{4}\right] \\
\leqq & 8 \cdot 36 E\left[u \int_{0}^{u}\left\{\left(f\left\{t, s, x_{1}(s)\right)-f\left(t, s, x_{2}(s)\right)\right)-\left(f\left(u, s, x_{1}(s)\right)-f\left(u, s, x_{2}(s)\right)\right)\right\}^{4} d s\right. \\
& \left.+(t-u) \int_{u}^{t}\left\{f\left(t, s, x_{1}(s)\right)-f\left(t, s, x_{2}(s)\right)\right\}^{4} d s\right] \\
= & 8 \cdot 36\left(I_{1}+I_{2}\right) .
\end{aligned}
$$


Using the assumptions (A3), (A4) and (A5), we obtain

$$
\begin{gathered}
I_{1} \leqq E\left[u \int_{0}^{u}\left\{2\left(f\left(t, s, x_{1}(s)\right)-f\left(t, s, x_{2}(s)\right)\right)^{2}+2\left(f\left(u, s, x_{1}(s)\right)-f\left(u, s, x_{2}(s)\right)\right)^{2}\right\}\right. \\
\left.\quad \times\left\{2\left(f\left(t, s, x_{1}(s)\right)-f\left(u, s, x_{1}(s)\right)\right)^{2}+2\left(f\left(t, s, x_{2}(s)\right)-f\left(u, s, x_{2}(s)\right)\right)^{2}\right\} d s\right] \\
\leqq E\left[T \int_{0}^{T} 4 K^{2}\left|x_{1}(s)-x_{2}(s)\right|^{2} \times 4 K^{2}|t-u|^{2} d s\right] \\
\leqq 16 K^{4} T^{2} \sup _{0 \leqq s \leqq T} E\left[\left|x_{1}(s)-x_{2}(s)\right|^{2}\right](t-u)^{2} . \\
I_{2} \leqq E\left[(t-u) \int_{u}^{t} K^{4}\left|x_{1}(s)-x_{2}(s)\right|^{4} d s\right] \\
\leqq K^{4} \sup _{0 \leqq s \leqq T} E\left[\left|x_{1}(s)-x_{2}(s)\right|^{4}\right](t-u)^{2} .
\end{gathered}
$$

Therefore, from (2.3), (2.4) and (2.5), we have

$$
\begin{aligned}
& E\left[|J(t)-J(u)|^{4}\right] \\
\leqq & 8 \cdot 36 K^{4}\left(16 T^{2} \sup _{0 \leqq s \leqq T} E\left[\left|x_{1}(s)-x_{2}(s)\right|^{2}\right]+\sup _{0 \leqq s \leqq T} E\left[\left|x_{1}(s)-x_{2}(s)\right|^{4}\right]\right)(t-u)^{2} .
\end{aligned}
$$

To complete the proof, we have only to use the above estimate (2.6) instead of the estimate (9) in [4] and proceed in a completely analogous manner to the proof of Lemma 1 in [4].

The following lemma can be also derived by a completely similar method using the estimate (2.2), hence the proof is omitted. We must, however, remark that the assumption (A4) is not necessary in Lemma 2.3.

LEMmA 2.3. If $x(t)$ satısfies $\sup _{0 \leqq t \leqq T} E\left[x^{4}(t)\right]<\infty$, then

$$
P\left(\sup _{0 \leqq t \leqq T}\left|\int_{0}^{t} f(t, s, x(s)) d B(s)\right| \geqq \lambda\right) \leqq \lambda^{-4} K_{0} T^{2} C_{2},
$$

where $K_{0}$ is an absolute constant and

$$
C_{2}=288 K^{4}\left(T^{4}+8+8 \sup _{0 \leq s \leq T} E\left[x^{4}(s)\right]\right) .
$$

Finally we note that another integral transformation

$$
\int_{0}^{t} f(t, s, x(s)) d s, \quad 0 \leqq t \leqq T,
$$

is $F_{t}$-adapted and continuous in $t$ under the assumptions (A1)-(A4).

\section{Existence and Uniqueness of Solutions}

The aim of this section is to establish the existence and uniqueness theorem for the solutions of stochastic integral equations (I), which corresponds to the 
well-known theorem for the solutions of stochastic differential equations (see [2], [3]).

THEOREM 3.1. Suppose that $f(t, s, x)$ satisfies the assumptions (A1)-(A5) and that $g(t, s, x)$ satisfies the assumptions (A1)-(A4). If $\phi(t)$ is a $F_{t}$-adapted continuous process with $\sup _{0 \leq t \leq T} E\left[\phi^{4}(t)\right]<\infty$, then there exists a unique solution $x(t)$ of (I) satisfying $\sup _{0 \leq t \leq T} E\left[x^{2}(t)\right]<\infty$.

Proof. We prove this assertion using a method similar to the standard method in the theory of stochastic differential equations. First to prove the existence of a solution $x(t)$, we use the method of successive approximations.

We define $x_{0}(t)=\phi(t)$ and

$$
x_{n}(t)=\phi(t)+\int_{0}^{t} f\left(t, s, x_{n-1}(s)\right) d B(s)+\int_{0}^{t} g\left(t, s, x_{n-1}(s)\right) d s .
$$

Then we have

$$
\begin{aligned}
& x_{n+1}(t)-x_{n}(t) \\
= & \int_{0}^{t}\left\{f\left(t, s, x_{n}(s)\right)-f\left(t, s, x_{n-1}(s)\right)\right\} d B(s) \\
& +\int_{0}^{t}\left\{g\left(t, s, x_{n}(s)\right)-g\left(t, s, x_{n-1}(s)\right)\right\} d s .
\end{aligned}
$$

Taking the expectation of the squares of (3.1) and using (A4), we obtain

$$
\begin{aligned}
& E\left[\left|x_{n+1}(t)-x_{n}(t)\right|^{2}\right] \\
\leqq & 2 E\left[\left|\int_{0}^{t}\left\{f\left(t, s, x_{n}(s)\right)-f\left(t, s, x_{n-1}(s)\right)\right\} d B(s)\right|^{2}\right] \\
& +2 E\left[\left|\int_{0}^{t}\left\{g\left(t, s, x_{n}(s)\right)-g\left(t, s, x_{n-1}(s)\right)\right\} d s\right|^{2}\right] \\
\leqq & 2 K^{2} E\left[\int_{0}^{t}\left|x_{n}(s)-x_{n-1}(s)\right|^{2} d s\right]+2 K^{2} t E\left[\int_{0}^{t}\left|x_{n}(s)-x_{n-1}(s)\right|^{2} d s\right] \\
\leqq & M \int_{0}^{t} E\left[\left|x_{n}(s)-x_{n-1}(s)\right|^{2}\right] d s,
\end{aligned}
$$

where $M=2 K^{2}(T+1)$. On the other hand, using (A3), we have

$$
\begin{aligned}
& E\left[\left|x_{1}(t)-x_{0}(t)\right|^{2}\right] \\
= & E\left[\left|\int_{0}^{t} f(t, s, \phi(s)) d B(s)+\int_{0}^{t} g(t, s, \phi(s)) d s\right|^{2}\right] \\
\leqq & 2 M \int_{0}^{t} E\left[1+\phi^{2}(s)\right] d s \\
\leqq & 2 M \mu_{2} t,
\end{aligned}
$$


where $\mu_{2}=\sup _{0 \leqq t \leqq T} E\left[1+\phi^{2}(t)\right]<\infty$. This together with (3.2) yields

$$
E\left[\left|x_{n+1}(t)-x_{n}(t)\right|^{2}\right] \leqq 2 \mu_{2}(M t)^{n+1} /(n+1) ! .
$$

Similarly, taking fourth powers in (3.1) and taking the expectation, we have

$$
\begin{aligned}
& E\left[\left|x_{n+1}(t)-x_{n}(t)\right|^{4}\right] \\
\leqq & 8 E\left[\left|\int_{0}^{t}\left\{f\left(t, s, x_{n}(s)\right)-f\left(t, s, x_{n-1}(s)\right)\right\} d B(s)\right|^{4}\right] \\
& +8 E\left[\left|\int_{0}^{t}\left\{g\left(t, s, x_{n}(s)\right)-g\left(t, s, x_{n-1}(s)\right)\right\} d s\right|^{4}\right] \\
\leqq & 8 \cdot 36 E\left[t \int_{0}^{t}\left\{f\left(t, s, x_{n}(s)\right)-f\left(t, s, x_{n-1}(s)\right)\right\}^{4} d s\right] \\
& +8 E\left[t^{3} \int_{0}^{t}\left\{g\left(t, s, x_{n}(s)\right)-g\left(t, s, x_{n-1}(s)\right)\right\}^{4} d s\right] \\
\leqq & 8 K^{4} T\left(36+T^{2}\right) \int_{0}^{t} E\left[\left|x_{n}(s)-x_{n-1}(s)\right|^{4}\right] d s \\
= & N \int_{0}^{t} E\left[\left|x_{n}(s)-x_{n-1}(s)\right|^{4}\right] d s,
\end{aligned}
$$

where $N=8 K^{4} T\left(36+T^{2}\right)$. On the other hand, we get

$$
\begin{aligned}
& E\left[\left|x_{1}(t)-x_{0}(t)\right|^{4}\right] \\
\leqq & 8 \int_{0}^{t} E\left[1+\phi^{4}(s)\right] d s \\
\leqq & 8 N \mu_{4} t,
\end{aligned}
$$

where $\mu_{4}=\sup _{0 \leq t \leq T} E\left[1+\phi^{4}(t)\right]<\infty$. This together with (3.4) yields

$$
E\left[\left|x_{n+1}(t)-x_{n}(t)\right|^{4}\right] \leqq 8 \mu_{4}(N t)^{n+1} /(n+1) ! .
$$

Thus all $x_{n}(t)$ successively defined are well defined and, moreover, they are $F_{t^{-}}$ adapted continuous processes owing to the continuity of $\phi(t)$.

Now taking suprema of the squares of (3.1) and using (A4), we get

$$
\begin{aligned}
& \sup _{0 \leqq t \leqq T}\left|x_{n+1}(t)-x_{n}(t)\right|^{2} \\
\leqq & 2 \sup _{0 \leqq t \leqq T}\left|\int_{0}^{t}\left\{f\left(t, s, x_{n}(s)\right)-f\left(t, s, x_{n-1}(s)\right)\right\} d B(s)\right|^{2} \\
& +2 \sup _{0 \leqq t \leqq T}\left|\int_{0}^{t}\left\{g\left(t, s, x_{n}(s)\right)-g\left(t, s, x_{n-1}(s)\right)\right\} d s\right|^{2} \\
\leqq & 2 \sup _{0 \leqq t \leqq T}\left|\int_{0}^{t}\left\{f\left(t, s, x_{n}(s)\right)-f\left(t, s, x_{n-1}(s)\right)\right\} d B(s)\right|^{2}
\end{aligned}
$$


164

ICHIRO ITO

$$
+2 T K^{2} \int_{0}^{T}\left|x_{n}(s)-x_{n-1}(s)\right|^{2} d s .
$$

Hence it follows that

$$
\begin{aligned}
& P\left(\sup _{0 \leq t \leqq T}\left|x_{n+1}(t)-x_{n}(t)\right|^{2}>\lambda\right) \\
\leqq & P\left(\sup _{0 \leq t \leqq T}\left|\int_{0}^{t}\left\{f\left(t, s, x_{n}(s)\right)-f\left(t, s, x_{n-1}(s)\right)\right\} d B(s)\right|^{2}>\lambda / 4\right) \\
& +P\left(\int_{0}^{T}\left|x_{n}(s)-x_{n-1}(s)\right|^{2} d s>\lambda /\left(4 T K^{2}\right)\right) .
\end{aligned}
$$

Applying Lemma 2.2 to the first term on the right-hand side of (3.6) and using (3.3) and (3.5), we obtain

$$
\begin{aligned}
& P\left(\sup _{0 \leqq t \leqq T}\left|\int_{0}^{t}\left\{f\left(t, s, x_{n}(s)\right)-f\left(t, s, x_{n-1}(s)\right)\right\} d B(s)\right|^{2}>\lambda / 4\right) \\
\leqq & 16 \lambda^{-2} K_{0} T^{2} 288 K^{4}\left(16 T^{2} \sup _{0 \leqq t \leqq T} E\left[\left|x_{n}(t)-x_{n-1}(t)\right|^{2}\right]\right. \\
& \left.+\sup _{0 \leqq t \leqq T} E\left[\left|x_{n}(t)-x_{n-1}(t)\right|^{4}\right]\right) \\
\leqq & 16 \lambda^{-2} K_{0} T^{2} 288 K^{4}\left(16 T^{2} \cdot 2 \mu_{2}(M T)^{n} / n !+8 \mu_{4}(N T)^{n} / n !\right) .
\end{aligned}
$$

As to the second term on the right-hand side of (3.6), the inequality of the Chebychev type implies that

$$
\begin{aligned}
& P\left(\int_{0}^{T}\left|x_{n}(s)-x_{n-1}(s)\right|^{2} d s>\lambda /\left(4 T K^{2}\right)\right) \\
\leqq & 4 \lambda^{-1} T K^{2} E\left[\int_{0}^{T}\left|x_{n}(s)-x_{n-1}(s)\right|^{2} d s\right] \\
\leqq & 4 \lambda^{-1} T^{2} K^{2} \cdot 2 \mu_{2}(M T)^{n} / n ! .
\end{aligned}
$$

Inserting (3.7) and (3.8) with $\lambda=4^{-n}$ into (3.6), we find that

$$
\begin{aligned}
& P\left(\sup _{0 \leqq t \leqq T}\left|x_{n+1}(t)-x_{n}(t)\right|>2^{-n}\right) \\
\leqq & \text { const. }(16 M T)^{n} / n !+\text { const. }(16 N T)^{n} / n !+\text { const. }(4 M T)^{n} / n ! .
\end{aligned}
$$

Since the right-hand side of (3.9) is a general term of a convergent series, the Borel-Cantelli lemma implies that

$$
P\left(\sup _{0 \leqq t \leqq T}\left|x_{n+1}(t)-x_{n}(t)\right| \leqq 2^{-n}, n \uparrow \infty\right)=1 .
$$

It follows that the partial sums

$$
\sum_{k=0}^{n-1}\left(x_{k+1}(t)-x_{k}(t)\right)+\phi(t)=x_{n}(t)
$$


are convergent uniformly in $t \in[0, T]$ with probability one. We denote the limit by $x(t)$. Since all $x_{n}(t)$ are $F_{t}$-adapted and continuous, so is the uniform limit of $x_{n}(t)$. It is clear that $x(t)$ satisfies the stochastic integral equation (I), by the routine argument in the theory of stochastic integrals if only we apply the maximal inequality in Lemma 2.2 in place of the martingale inequality. Therefore the assertion of existence is proved.

It remains to prove the uniqueness. Suppose $x(t)$ and $y(t)$ are two solutions of (I), then

$$
\begin{aligned}
x(t)-y(t)= & \int_{0}^{t}(f(t, s, x(s))-f(t, s, y(s))) d B(s) \\
& +\int_{0}^{t}(g(t, s, x(s))-g(t, s, y(s))) d s .
\end{aligned}
$$

Using an analogous estimate to (3.2), we have

$$
E\left[|x(t)-y(t)|^{2}\right]=2 K^{2}(T+1) \int_{0}^{t} E\left[|x(s)-y(s)|^{2}\right] d s .
$$

Applying the Gronwall inequality, we find that

$$
E\left[|x(t)-y(t)|^{2}\right] \equiv 0 \text {. }
$$

It follows that

$$
P(x(t)=y(t))=1 \quad \text { for each } t \in[0, T] .
$$

Since both processes $x(t)$ and $y(t)$ are continuous, we conclude that

$$
P(x(t)=y(t) \quad \text { for all } t \in[0, T])=1 .
$$

This completes the proof of uniqueness.

COROLlaRY. Under the assumptions of Theorem 3.1,

$$
\begin{aligned}
& E\left[x^{2}(t)\right] \leqq\left(3 \sup _{0 \leqq s \leqq T} E\left[\phi^{2}(s)\right]+1\right) \exp \left(6 K^{2}(1+T) t\right)-1, \\
& E\left[x^{4}(t)\right] \leqq\left(27 \sup _{0 \leqq s \leqq T} E\left[\phi^{4}(s)\right]+1\right) \exp \left(216 K^{4} T\left(36+T^{2}\right) t\right)-1 .
\end{aligned}
$$

Remark. The constant $K$ on the right-hand side of the above estimates is determined only by the growth condition (A3) with respect to $f$ and $g$.

Proof of Corollary. Taking the expectation of the squares in (I) and using (A3), we have

$$
E\left[x^{2}(t)\right] \leqq 3 E\left[\phi^{2}(t)\right]+6 K^{2}(1+T) \int_{0}^{t} E\left[1+x^{2}(s)\right] d s .
$$

Hence,

$$
E\left[1+x^{2}(t)\right] \leqq\left(3 \sup _{0 \leqq s \leqq T} E\left[\phi^{2}(s)\right]+1\right)+6 K^{2}(1+T) \int_{0}^{t} E\left[1+x^{2}(s)\right] d s .
$$


Applying the Gronwall inequality, we find that

$$
E\left[1+x^{2}(t)\right] \leqq\left(3 \sup _{0 \leqq s \leqq T} E\left[\phi^{2}(s)\right]+1\right) \exp \left(6 K^{2}(1+T) t\right) .
$$

Thus the first estimate is obtained.

It remains to show the latter. Taking fourth powers in (I) and then taking the expectation and using (A3), we get

$$
E\left[x^{4}(t)\right] \leqq 27 E\left[\phi^{4}(t)\right]+216 K^{4} T\left(36+T^{2}\right) \int_{0}^{t} E\left[1+x^{4}(s)\right] d s .
$$

Hence, similarly as above, we obtain the desired estimate. This completes the proof.

\section{Stronger Uniqueness and Existence}

In this section we prove stronger results for the existence and uniqueness than in section 3. For this purpose, we now establish a local uniqueness theorem.

THEOREM 4.1. Suppose that $f_{i}(t, s, x)(\imath=1,2)$ satısfies the assumptrons (A1)(A5), that $g_{i}(t, s, x)(\imath=1,2)$ satisfies the assumptions (A1)-(A4), and that for some $N>0 f_{1}(t, s, x)=f_{2}(t, s, x)$ and $g_{1}(t, s, x)=g_{2}(t, s, x)$ if $|x| \leqq N, 0 \leqq s \leqq t \leqq T$. Assume that $\phi(t)$ satisfies the conditions of Theorem 3.1. Let $x_{i}(t)(i=1,2)$ be the solution of the equation

$$
x_{i}(t)=\phi(t)+\int_{0}^{t} f_{i}\left(t, s, x_{i}(s)\right) d B(s)+\int_{0}^{t} g_{i}\left(t, s, x_{i}(s)\right) d s, \quad 0 \leqq t \leqq T,
$$

with $\sup _{0 \leqq t \leqq T} E\left[x_{\imath}{ }^{2}(t)\right]<\infty$. Denote by $\tau_{\imath}$ the largest value of $t \leqq T$ for which $\sup _{0 \leq s \leq t}\left|x_{i}(s)\right|<\infty$. Then

$$
\begin{aligned}
& P\left(\tau_{1}=\tau_{2}\right)=1, \\
& P\left(\sup _{0 \leqq s \leqq \tau_{1}}\left|x_{1}(s)-x_{2}(s)\right|=0\right)=1 .
\end{aligned}
$$

Proof. This theorem can be proved after the manner of the theory of stochastic differential equations. Hence we only sketch the proof.

Let $\phi_{i}(t)=1$ if $\sup _{0 \leq s \leq t}\left|x_{i}(s)\right| \leqq N$ and $\phi_{i}(t)=0$ otherwise. Then, noting that $\phi_{1}(t)=1$ implies $f_{1}\left(t, s, x_{1}(s)\right)=f_{2}\left(t, s, x_{1}(s)\right)$ and $g_{1}\left(t, s, x_{1}(s)\right)=g_{2}\left(t, s, x_{1}(s)\right)$ for $s \leqq t$, we have

$$
\begin{aligned}
& \psi_{1}(t)\left|x_{1}(t)-x_{2}(t)\right|^{2} \\
\leqq & 2 \psi_{1}(t)\left|\int_{0}^{t}\left\{f_{2}\left(t, s, x_{1}(s)\right)-f_{2}\left(t, s, x_{2}(s)\right)\right\} d B(s)\right|^{2} \\
& +2 \psi_{1}(t)\left|\int_{0}^{t}\left\{g_{2}\left(t, s, x_{1}(s)\right)-g_{2}\left(t, s, x_{2}(s)\right)\right\} d s\right|^{2} .
\end{aligned}
$$


Since $\phi_{1}(t)=1$ implies $\phi_{1}(s)=1$ for $s \leqq t$,

$$
\begin{aligned}
& \phi_{1}(t)\left|x_{1}(t)-x_{2}(t)\right|^{2} \\
\leqq & 2\left|\int_{0}^{t} \phi_{1}(s)\left\{f_{2}\left(t, s, x_{1}(s)\right)-f_{2}\left(t, s, x_{2}(s)\right)\right\} d B(s)\right|^{2} \\
& +2\left|\int_{0}^{t} \phi_{1}(s)\left\{g_{2}\left(t, s, x_{1}(s)\right)-g_{2}\left(t, s, x_{2}(s)\right)\right\} d s\right|^{2} .
\end{aligned}
$$

Taking the expectation and using (A4), we get

$$
E\left[\psi_{1}(t)\left|x_{1}(t)-x_{2}(t)\right|^{2}\right] \leqq 2 K^{2}(1+T) \int_{0}^{T} E\left[\psi_{1}(s)\left|x_{1}(s)-x_{2}(s)\right|^{2}\right] d s .
$$

Applying the Gronwall inequality and using the continuity of $x_{1}(t)$ and $x_{2}(t)$, we obtain

$$
P\left(\sup _{0 \leqq t \leqq T} \psi_{1}(t)\left|x_{1}(t)-x_{2}(t)\right|=0\right)=1 .
$$

It follows that $x_{1}(t)=x_{2}(t)$ w. p. 1 if $0 \leqq t \leqq \tau_{1}$. Consequently $P\left(\tau_{1} \leqq \tau_{2}\right)=1$. Similarly $P\left(\tau_{1} \geqq \tau_{2}\right)=1$, and the theorem is proved.

We now intend to improve Theorem 3.1. Using Theorem 4.1, we can establish an existence and uniqueness theorem under weaker conditions than in Theorem 3.1.

THEOREm 4.2. Suppose that $f(t, s, x)$ and $g(t, s, x)$ satisfy the assumption (A1)-(A3) and

(A4') for any $N>0$ there is a positwe constant $K_{N}$ such that

$$
\begin{aligned}
& \left|f\left(t, s, x_{1}\right)-f\left(t, s, x_{2}\right)\right| \leqq K_{N}\left|x_{1}-x_{2}\right|, \\
& \left|g\left(t, s, x_{1}\right)-g\left(t, s, x_{2}\right)\right| \leqq K_{N}\left|x_{1}-x_{2}\right| \\
& \text { if }\left|x_{1}\right| \leqq N,\left|x_{2}\right| \leqq N, 0 \leqq s \leqq t \leqq T,
\end{aligned}
$$

and moreover $f(t, s, x)$ satısfies (A5). If $\phi(t)$ is a $F_{t}$-adapted continuous process with $\sup _{0 \leq t \leqq T} E\left[\phi^{4}(t)\right]<\infty$, then there exists a unque solution $x(t)$ of (I) satısfyng $\sup _{0 \leqq t \leqq T} E\left[x^{2}(t)\right]<\infty$.

Remark. This theorem asserts that the assumption (A4) can be replaced by the weaker assumption ( $\left.4^{\prime}\right)$ also assuring the existence of a unique solution of (I).

Proof. We first show the existence of a solution. Let

$$
f_{N}\left(t^{\prime}, s, x\right)=\left\{\begin{array}{lll}
f(t, s, x) & \text { if } \quad|x| \leqq N, \\
f(t, s, x)(2-|x| / N) & \text { if } \quad N<|x| \leqq 2 N, \\
0 & \text { if } \quad|x|>2 N,
\end{array}\right.
$$




$$
g_{N}(t, s, x)=\left\{\begin{array}{lll}
g(t, s, x) & \text { if } & |x| \leqq N, \\
g(t, s, x)(2-|x| / N) & \text { if } & N<|x| \leqq 2 N, \\
0 & \text { if } & |x|>2 N .
\end{array}\right.
$$

Then $f_{N}(t, s, x)$ and $g_{N}(t, s, x)$ satisfy all the assumptions in Theorem 3.1. Therefore Theorem 3.1 asserts that there exists a unique solution $x_{N}(t)$ satisfying $\sup _{0 \leq t \leq T} E\left[x_{N}^{2}(t)\right]<\infty$ of

$$
x_{N}(t)=\phi(t)+\int_{0}^{t} f_{N}\left(t, s, x_{N}(s)\right) d B(s)+\int_{0}^{t} g_{N}\left(t, s, x_{N}(s)\right) d s .
$$

Taking suprema in (4.3), we have

$$
\begin{aligned}
\sup _{0 \leqq t \leqq T}\left|x_{N}(t)\right| \leqq \sup _{0 \leqq t \leqq T}|\phi(t)| & +\sup _{0 \leqq t \leqq T}\left|\int_{0}^{t} f_{N}\left(t, s, x_{N}(s)\right) d B(s)\right| \\
& +\sup _{0 \leqq t \leqq T}\left|\int_{0}^{t} g_{N}\left(t, s, x_{N}(s)\right) d s\right| .
\end{aligned}
$$

Hence,

$$
\begin{aligned}
P\left(\sup _{0 \leqq t \leqq T}\left|x_{N}(s)\right|>N\right) \leqq & P\left(\sup _{0 \leqq t \leqq T}|\phi(t)|>N / 3\right) \\
& +P\left(\sup _{0 \leqq t \leqq T}\left|\int_{0}^{t} f_{N}\left(t, s, x_{N}(s)\right) d B(s)\right|>N / 3\right) \\
& +P\left(\sup _{0 \leqq t \leqq T}\left|\int_{0}^{t} g_{N}\left(t, s, x_{N}(s)\right) d s\right|>N / 3\right) .
\end{aligned}
$$

Now the continuity of $\phi(t)$ with probability one implies that

$$
P\left(\sup _{0 \leqq t \leqq T}|\phi(t)|>N / 3\right) \longrightarrow 0 \quad \text { as } \quad N \rightarrow \infty .
$$

On the other hand, since $\left|g_{N}(t, s, x)\right| \leqq|g(t, s, x)| \leqq K(1+|x|)$ by (4.2) and (A3),

$$
\sup _{0 \leqq t \leqq T}\left|\int_{0}^{t} g_{N}\left(t, s, x_{N}(s)\right) d s\right|^{2} \leqq 2 K^{2} T \int_{0}^{T}\left(1+x_{N}{ }^{2}(s)\right) d s .
$$

Therefore, applying the Chebychev inequality and using the Corollary of Theorem 3.1, we obtain

$$
\begin{aligned}
& P\left(\sup _{0 \leqq t \leqq T}\left|\int_{0}^{t} g_{N}\left(t, s, x_{N}(s)\right) d s\right|>N / 3\right) \\
\leqq & 9 N^{-2} E\left[2 K^{2} T \int_{0}^{T}\left(1+x_{N}^{2}(s)\right) d s\right] \\
= & \text { const. } N^{-2} \longrightarrow 0 \quad \text { as } N \rightarrow \infty .
\end{aligned}
$$

As for the second term on the right-hand side of (4.4), applying Lemma 2.3 and using the Corollary of Theorem 3.1, we find 


$$
\begin{aligned}
& P\left(\sup _{0 \leqq t \leqq T}\left|\int_{0}^{t} f_{N}\left(t, s, x_{N}(s)\right) d B(s)\right|>N / 3\right) \\
\leqq & 81 N^{-4} K_{0} T^{2} \cdot 288 K^{4}\left(T^{4}+8+8 \sup _{0 \leqq s \leqq T} E\left[x_{N}{ }^{4}(s)\right]\right) \\
= & \text { const. } N^{-4} \longrightarrow 0 \quad \text { as } \quad N \rightarrow \infty .
\end{aligned}
$$

These facts (4.5), (4.6) and (4.7) together with (4.4) imply that

$$
\lim _{N \rightarrow \infty} P\left(\sup _{0 \leq t \leq T}\left|x_{N}(t)\right|>N\right)=0 \text {. }
$$

Let $\tau_{N}$ be the largest value of $t$ for which $\sup _{0 \leqq s \leqq t}\left|x_{N}(s)\right| \leqq N$. If $N^{\prime}>N$, then Theorem 4.1 asserts that $x_{N}(t)=x_{N^{\prime}}(t)$ w. p. 1 if $0 \leqq t \leqq \tau_{N}$. Therefore

$$
P\left(\sup _{0 \leqq t \leqq T}\left|x_{N}(t)-x_{N^{\prime}}(t)\right|>0\right) \leqq P\left(\tau_{N}<T\right)=P\left(\sup _{0 \leqq t \leqq T}\left|x_{N}(t)\right|>N\right) .
$$

This together with (4.8) implies that $x_{N}(t)$ converges uniformly with probability one to some limit $x(t)$ as $N \rightarrow \infty$. Since it is clear that we can pass to the limit in (4.3), we conclude that $x(t)$ is a solution of (I).

We now prove the uniqueness. Let $x_{1}(t)$ and $x_{2}(t)$ be two continuous solutions of (I) with $\sup _{0 \leqq t \leqq T} E\left[x_{\imath}^{2}(t)\right]<\infty(\imath=1,2)$. Let

$$
\phi(t)= \begin{cases}1 & \text { if } \sup _{0 \leqq s \leqq t}\left|x_{1}(s)\right| \leqq N, \sup _{0 \leqq s \leqq t}\left|x_{2}(s)\right| \leqq N, \\ 0 & \text { otherwise } .\end{cases}
$$

Then, using $\left(\mathrm{A} 4^{\prime}\right)$ and a similar method to the proof of Theorem 4.1, we obtain

$$
E\left[\psi(t)\left|x_{1}(t)-x_{2}(t)\right|^{2}\right] \leqq 4 K_{N}^{2}(1+T) \int_{0}^{t} E\left[\psi(s)\left|x_{1}(s)-x_{2}(s)\right|^{2}\right] d s .
$$

Hence

$$
E\left[\phi(t)\left|x_{1}(t)-x_{2}(t)\right|^{2}\right]=0
$$

It follows that

$$
P\left(x_{1}(t) \neq x_{2}(t)\right) \leqq P\left(\sup _{0 \leqq s \leqq T}\left|x_{1}(s)\right|>N\right)+P\left(\sup _{0 \leqq s \leqq T}\left|x_{2}(s)\right|>N\right) .
$$

Since both $x_{1}(t)$ and $x_{2}(t)$ are continuous processes, the right-hand side of this inequality tends to zero as $N \rightarrow \infty$. Therefore

$$
P\left(x_{1}(t) \neq x_{2}(t)\right)=0 \text {. }
$$

Consequently, again from the continuity of $x_{1}(t)$ and $x_{2}(t)$, we conclude that

$$
P\left(x_{1}(t)=x_{2}(t) \text { for } 0 \leqq t \leqq T\right)=1 \text {. }
$$

This completes the proof. 


\section{REFERENCES}

[1] A. T. Bharucha-Reid, Random Integral Equations, Academic Press, New York, 1972.

[2] A. Friedman, Stochastic Differential Equations and Applications, Vol. 1, Academic Press, New York, 1975.

[3] I. I. Gihman And A. V. Skorohod, Stochastic Differential Equations, Springer, New York, 1972.

[4] I. Iто, On Linear Stochastic Integral Equations of the Volterra Type, Research Reports on Information Sciences, Series A-47, Tokyo Institute of Technology, 1977.

[5] R.K. MilleR, Nonlinear Volterra Integral Equations, Benjamin, California, 1971.

[6] A.N.V. RaO AND C.P. Tsokos, On the Existence of a Random Solution to a Nonlinear Perturbed Stochastic Integral Equation, Ann. Inst. Statist. Math., 28 (1976) 99-109.

[7] C.P. Tsokos AND W.J. Padgett, Random Integral Equations with Applications to Life Sciences and Engineering, Academic Press, New York, 1974.

Tokyo Institute of Technology

Present address :

Tokyo Gakugei University

4-1-1 NukUi Kita-Machi,

KOGANEI-ShI, TOKYO, JAPAN 